\title{
The Cordierite Formation in Mechanically Activated Talc-Kaoline-Alumina-Basalt-Quartz Ceramic System
}

\author{
D. Kirsever*, N. Karakus, N. Toplan, H.O. Toplan \\ Sakarya University, Metalurgy and Materials Engineering, 54187 Sakarya, Turkey
}

\begin{abstract}
The powder mixtures of Talc-Kaolinite-Alumina-Basalt-Quartz were mechanically activated in a planetary ball mill for 1 hour. The structural alterations and thermal behaviour of the powder mixture were examined by X-ray diffraction (XRD), scanning electron microscopy (SEM) and thermal analysis (TG-DTA). The results showed that the mechanical activation led to amorphisation and decreased the temperature of cordierite formation.
\end{abstract}

DOI: $10.12693 /$ APhysPolA.127.1042

PACS: 81.05.Je

\section{Introduction}

Cordierite, which chemical composition is $2 \mathrm{MgO} \cdot 2 \mathrm{Al}_{2} \mathrm{O}_{3} \cdot 5 \mathrm{SiO}_{2}$, is one of the phases of the ternary $\mathrm{MgO}-\mathrm{SiO}_{2}-\mathrm{Al}_{2} \mathrm{O}_{3}$ system, along with mullite, cristobalite, tridymite, enstatite, forsterite, sapphirine, etc. Cordierite-based materials have a great importance in modern technology due to their excellent properties, such as low thermal expansion coefficient, high refractoriness, low dielectric constant, high thermal shock resistance and good mechanical properties [1]. There are several methods to synthesize cordierite, such as solidstate reaction, sol-gel and crystallization from glass. Different processes remarkably influence the reactivity of the solids. Mechanical treatments are important as long as they can help produce the changes in the texture and structure of the solids, causing the particle size reduction and decreasing the reaction sintering temperature. Additives can also decrease the temperature of the reaction process during sintering. The application of additives should improve the contact between reacting components [2]. Conventionally, cordierite was prepared, as the main phase, from raw materials such as talc, kaolin, and magnesite [3]. Cordierite ceramics were prepared from the mixtures of clay minerals and also silica sand or technical silica and feldspar. Special compact cordierite ceramics was prepared from kaolinite and magnesium compounds. Cordierite ceramics prepared from halloysite and talc and from kaolinite and talc were used as automotive catalysts that promote purification of the exhaust gas. Low thermal expansion cordierite ceramics were manufactured with the addition of zircon $\left(\mathrm{ZrSiO}_{4}\right)$ to the magnesium aluminosilicate system. A suitable cordierite material enriched with zircon was suggested to be used instead of cordierite ceramic filters that degrade at high temperatures due to oxides in diesel soot [4]. Mechanical activation is a solid-state powder processing technique that involves repeated cold welding, fracturing, and rewelding of powder particles in

*corresponding author; e-mail: dkirsever@sakarya.edu.tr a high-energy ball mill. In this process, a small quantity of the blended elemental powder mixture is loaded into a container, along with the grinding media, and the whole mass is agitated at a high speed for a predetermined length of time [5]. The mechano-activation treatment might promote: the amorphization of treated material, noticeable change of the microstructure, size and shape of particles, etc. Furthermore, ultra-fine grinding kinetic investigation indicates the mechano-chemical reduction of the original particles of talc/mica, which appears to have reached a limit at grinding time of $30 \mathrm{~min}$. However, longer grinding times might produce an apparent increase in particle size [6].

In this study, the effects of mechanical activation on the formation of cordierite were analyzed in the talc, kaoline, alumina, basalt and quartz ceramics system using differential thermal analysis (DTA), X-ray diffraction (XRD) and scanning electron microscopy (SEM).

\section{Experimental}

Talc, alumina, kaoline and quartz were supplied from Kale Ceramic Company, Turkey. Basalt is a natural rock, from Konya area, Turkey. The chemical composition of raw materials is given in Table I. Talc, alumina, kaolinite, basalt and quartz were mixed stoichiometrically, according to chemical formula of cordierite (15 wt.\% quartz, 35 wt.\% talc, 15 wt. $\%$ kaoline, 11 wt.\% basalt, 25 wt.\% alumina) in ashless rubber-lined ceramic jars for $2 \mathrm{~h}$, using zirconia balls and distilled water as the milling media. After drying, the mixture was carried to a highenergy planetary ball mill (Fristch) with a rotation speed of $600 \mathrm{rpm}$. Ball-to-powder weight ratio was adjusted to 20. The precursor milling was carried out for 1 hour. Xray diffraction analysis was performed using a Rigaku Ultima X-ray diffractometer with $\mathrm{CuK}_{\alpha}$ radiation. A Joel $6060 \mathrm{LV}$ scanning electron microscope was used for morphological analysis of non-activated and activated mixed powders.

After activation, both non-activated and activated powders were sintered in an electrical furnace with a heating rate of $10^{\circ} \mathrm{C} / \mathrm{min}$ at 550, 650, 900, 1050, 1100, 1225 and $1325{ }^{\circ} \mathrm{C}$ for $1 \mathrm{~h}$. The formation of cordierite phase was examined by XRD and DTA. 
Chemical composition of raw materials.

TABLE I

\begin{tabular}{c|c|c|c|c|c}
\hline \hline & Talc & Kaolinite & Alumina & Quartz & Basalt \\
\hline $\mathrm{SiO}_{2}$ & 63.0 & 52.12 & - & 99.1 & 45.88 \\
$\mathrm{Al}_{2} \mathrm{O}_{3}$ & 0.40 & 33.83 & 100 & 0.28 & 18.20 \\
$\mathrm{Fe}_{2} \mathrm{O}_{3}$ & 0.25 & 0.55 & - & 0.05 & 9.95 \\
$\mathrm{CaO}$ & 0.40 & 0.15 & - & 0.10 & 9.28 \\
$\mathrm{~K}_{2} \mathrm{O}$ & 0.04 & 0.13 & - & - & 1.64 \\
$\mathrm{Na}_{2} \mathrm{O}$ & 0.08 & 0.01 & - & 0.17 & 4.76 \\
$\mathrm{MgO}$ & 30.0 & 0.05 & - & 0.06 & 6.62 \\
$\mathrm{TiO}_{2}$ & - & 0.45 & - & 0.05 & - \\
L.O.I.* & 4.78 & 12.45 & - & 0.19 & 3.67 \\
\end{tabular}

${ }^{*}$ Loss on ignition

\section{Results and discussion}

SEM micrographs of the non-activated and activated powders are presented in Fig. 1. As shown in these figures, the particle size of non-activated mixture is over $5 \mu \mathrm{m}$ (Fig. 1a). After mechanical activation, the agglomeration occurred. The XRD data given in Fig. 2 shows that all diffraction peaks get shorter after mechanical activation. This reflects the partial amorphisation and structural disordering in quartz, talc, kaoline, basalt and alumina. Mechanical activation has already been reported to amorphize materials [7]. DTA of non-activated and activated powder mixtures are given in Fig. 3 . The DTA curves in non-activated powder mixture show three endothermic effects, (a) at $515{ }^{\circ} \mathrm{C}$ due to dehydration of kaoline, (b) at $580{ }^{\circ} \mathrm{C}$ due to decomposition of talc and (e) above $1220{ }^{\circ} \mathrm{C}$, related to the formation of liquid phase that cannot be easily identified. These effects have disappeared in the activated powder mixture, due to the occurrence of dehydration of kaolinite, decomposition of talc and other effects during the mechanical activation. The none-activated powder mixtures showed three exothermic effects. The first effects (c) at about $870{ }^{\circ} \mathrm{C}$ may correspond to the crystallization of mullite from kaolin, the second one (d) at about $1000{ }^{\circ} \mathrm{C}$ is assigned to formation of $\mu$-cordierite, and the last one (f), at about $1295{ }^{\circ} \mathrm{C}$, has been identified as related to the formation of $\alpha$-cordierite. In the activated powder mixture the exothermic effect of formation of mullite has disappeared and the formation temperatures of $\mu$ cordierite (d') and $\alpha$-cordierite (f') are shifted to $938^{\circ} \mathrm{C}$ and $1195{ }^{\circ} \mathrm{C}$, respectively. These results are consistent with the results of Valaskova et al. [4], Neto et al. [8], Tamborenea et al. [9].

The XRD patterns of non-activated and activated powder mixtures annealed at $550{ }^{\circ} \mathrm{C}, 650{ }^{\circ} \mathrm{C}, 900{ }^{\circ} \mathrm{C}$, $1050{ }^{\circ} \mathrm{C}, 1100^{\circ} \mathrm{C}, 1225^{\circ} \mathrm{C}$ and $1325^{\circ} \mathrm{C}$ for $1 \mathrm{~h}$ (according to the effects of DTA) are illustrated in Fig. 4. The XRD patterns of none-activated powder mixtures (Fig. 4a) revealed five crystalline phases: talc, gismondine (form of basalt), enstatite, mullite and quartz between temperatures of $550{ }^{\circ} \mathrm{C}$ and $1100{ }^{\circ} \mathrm{C}$. For the first time, the cordierite crystalline phase appeared at $1225{ }^{\circ} \mathrm{C}$. Cordierite, enstiatite and mullite crystalline phases have

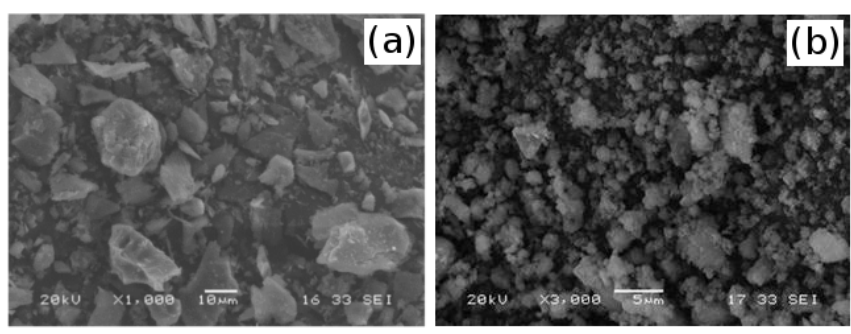

Fig. 1. SEM micrographs of non-activated (a), and activated (b) powder mixture.

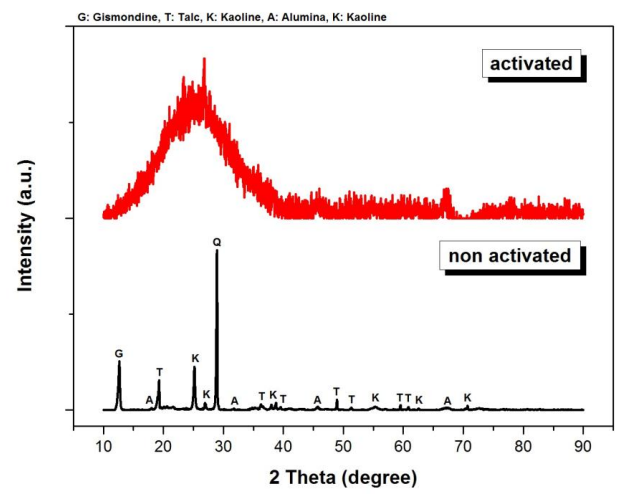

Fig. 2. XRD patterns of non-activated and activated powder mixture.

persisted to $1325^{\circ} \mathrm{C}$. These phases also occurred in the XRD patterns of activated powder mixture. However, the formation temperature of cordierite crystalline phase was lowered by mechanical activation to $1100{ }^{\circ} \mathrm{C}$. Mechanical treatment in a high energy mill generates a stress field within the solids. Stress relaxation can occur via several mechanisms: (1) heat release, (2) development of surface area, as a result of brittle fracture of the particles, (3) generation of various sorts of structural defects and (4) stimulation of chemical reactions within the solids. All of the relaxation channels cause changes in the reactivity of the solid substance under treatment, which is why the resulting action is called mechanical activa-

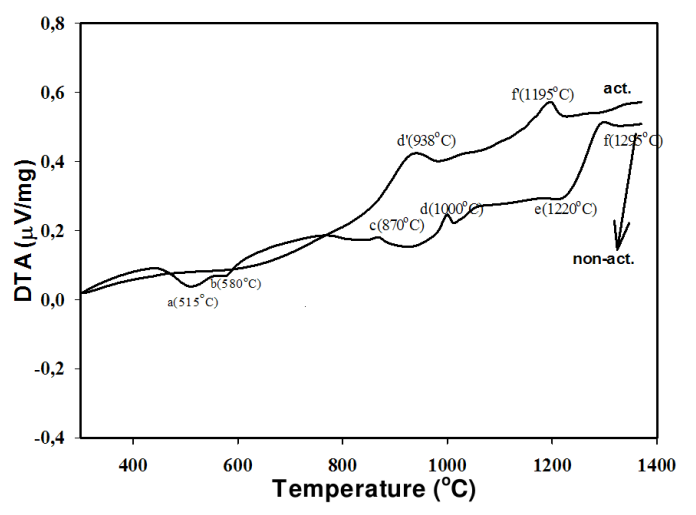

Fig. 3. DTA analyses of non-activated and activated powder mixture. 
tion [9]. The concentration of the mechanically induced defects and their spatial distribution depend upon the condition of the energy transfer in the mill. The creation of defects enhances the stored energy in the solids and consequently causes a decrease in the activation barrier for the further processing of the solids [10, 11].
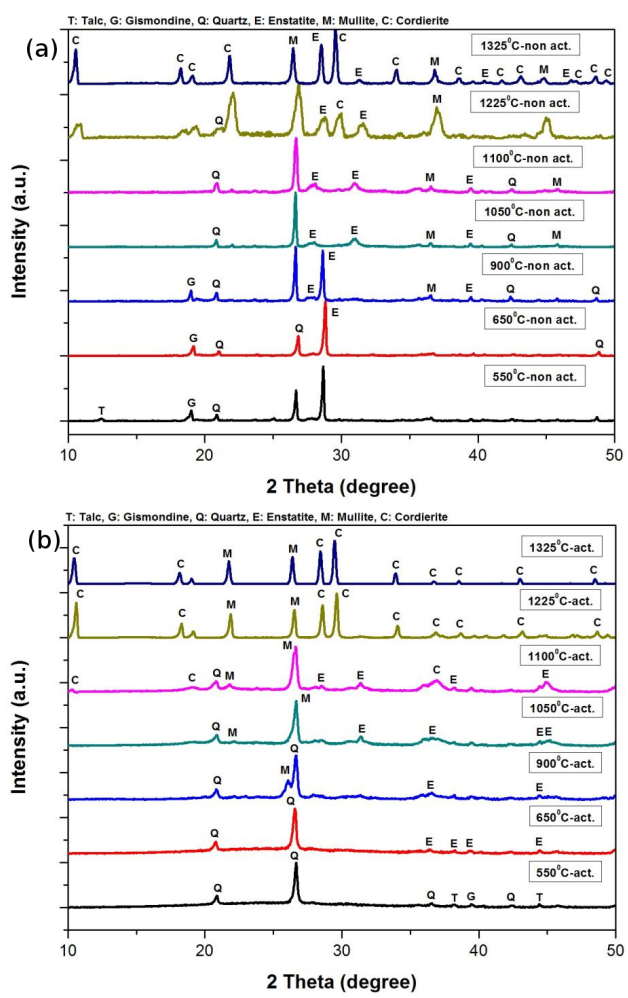

Fig. 4. XRD patterns of (a) none-activated and (b) activated powder mixture annealed at $550{ }^{\circ}-1325{ }^{\circ} \mathrm{C}$ for $1 \mathrm{~h}$.

\section{Conclusions}

The effects of mechanical activation on cordierite formation in talc-kaolinite-alumina-basalt-quartz ceramic system were studied by using DTA, XRD and SEM. The following results were obtained:
1. Mechanical activation has caused amorphisation and structural disordering in talc-kaolinite-aluminabasalt-quartz mixture.

2. Application of high energy milling allowed a dramatic change in the structure and surface performance of solids. Therefore, the temperature of cordierite formation was lowered by means of mechanical activation.

\section{Acknowledgments}

This work has been supported by Commission for Scientific Research Projects (BAPK) in Sakarya University (BAPK, project number: 2012-01-08-019).

\section{References}

[1] J.M. Benito, X. Turrillas, G.J. Cuello, A.H. De Aza, S. De Aza, M.A. Rodríguez, J. Euro. Ceram. Soc. 32, 371 (2012).

[2] N. Obradović, N. Đorđević, S. Filipović, N. Nikolić, D. Kosanović, M. Mitrić, S. Marković, V. Pavlović, Powder Technology 218, 157 (2012).

[3] E.M.A. Hamzawy, A.F. Ali, Materials Characterization 57, 414 (2006).

[4] M. Valášková, J. Zdrálková, G. Simha Martynková, B. Smetana, J. Vlček, S. Študentová, Ceram. Inter. 40, 8489 (2014).

[5] C. Suryanarayana, N. Al-Aqeeli, Progress in Materials Science 58, 383 (2013).

[6] L. Andrić, A. Terzić, Z. Aćimović-Pavlović, L. Pavlović, M. Petrov, Composites Part B: Engineering 59, 181 (2014).

[7] E. Elmas, K. Yıldız, N. Toplan H.Ö. Toplan, MTAEC9 47, 413 (2013).

[8] J.B.R. Neto, R. Moreno, Ceram. Inter. 37, 157 (2007).

[9] S. Tamborenea, A.D. Mazzoni, E.F. Aglietti, Thermo. Acta 411, 219 (2004).

[10] V.V. Boldyrev, T. Tkacova, J. Mater. Synt. Proc. 3-4, 121 (2000).

[11] U. Steinike, K. Tkacova, J. Mater. Synt. Proc. 8, 197 (2000). 